\title{
The public health management of tuberculosis among the single homeless: is mass miniature $x$ ray screening effective?
}

\author{
Andrew Stevens, Graham Bickler, Linda Jarrett, Nigel Bateman
}

\begin{abstract}
Study objective-The aim was to test the assumption that mass miniature $x$ ray screening of the single homeless (hostel residents) is a cost-effective means of controlling pulmonary tuberculosis.

Design-The study was a prospective experimental screening exercise to identify new cases of active tuberculosis completing treatment.
\end{abstract}

Setting-The setting was eight hostels in south London. A mobile $x$ ray screening facility was set up outside the hostels.

Subjects-Subjects were 547 single homeless residents in the hostels. They were encouraged to attend for chest $x$ ray, and for active follow up of abnormal $x$ rays.

Main results-No new cases of active tuberculosis were found.

Conclusions-Mass miniature $x$ ray is ineffective in controlling tuberculosis because of its unacceptability and increasing inaccessibility to this population.

Mass miniature radiography (MMR) was introduced in the $1940 \mathrm{~s}$ as a screening procedure for pulmonary tuberculosis for the general population. As the annual notification rate of tuberculosis in England and Wales declined from 1.0 per 1000 in 1945 to 0.1 per 1000 in $1986,{ }^{12}$ whole population screening was no longer considered necessary. ${ }^{3}$

In inner south east London, ie, Lambeth, Southwark and Lewisham, the incidence of tuberculosis also declined from 1.3 per 1000 in 1955 to $0 \cdot 2$ per 1000 in $1986,{ }^{2}$ though rates have always been higher than national ones. This excess incidence reflects a number of demographic features of inner city populations, including ethnicity, the concentration of single homeless people, and a degree of poverty and overcrowding.

Despite the moves to discontinue MMR from the early 1970s, the presumed continued screening needs of the "homeless and rootless" were recognised at the Department of Health and Social Security (DHSS). ${ }^{4}$ When plans to close the last remaining MMR in South East Thames were discussed it was strongly argued that the service needed to be sustained for homeless people living in hostels. The argument was not only that the incidence of tuberculosis among the single homeless was high but also that these people were less likely to be registered with a general practitioner and did not avail themselves of hospital services. ${ }^{4}$
Although these arguments and the position of the DHSS seemed reasonable, we decided to find out if a continued service was in fact justified. Six months after the closure of the main MMR service a further screening episode was set up early in 1987 to ascertain the yield and estimate the cost of a service to eight hostels for the single homeless in south east London.

\section{Methods}

A mobile MMR unit was made available to $x$ ray the residents of eight hostels for the single homeless in south east London and each hostel was visited once for a half day period. Strenuous efforts were made in order to maximise uptake. The timing of the visit was based on advice from each hostel's warden, publicity for the screening was organised, food inducements were given at the hostels not otherwise giving their residents a free meal, and one of the hostels organised a raffle with a $£ 15$ prize.

Data on each resident who had an $x$ ray were collected by a research worker specifically hired to accompany the MMR unit. The minature four inch postero-anterior $x$ rays were assessed by thoracic physicians at St Thomas's, Guy's, and Lewisham hospitals according to the addresses of the hostels. People with chest $x$ rays considered abnormal for any reason were given appointments to attend a chest clinic and these were sent to the appropriate hostels. Non-attenders were sent a further appointment via the hostel warden. A diagnosis of active tuberculosis was made on the basis of a positive sputum culture.

The yield was defined as the number of completed courses of antituberculosis treatment for new cases of tuberculosis discovered among the hostel dwellers. The cost was taken as that of a commercial firm providing miniature $x$ rays in occupational health settings, but did not include the cost of reading these $x$ rays or the subsequent outpatient attendances-to either the NHS or the client.

\section{Results}

The hostels were all residential and all male, except for one which had a younger, mixed, and non-residential clientele. The total hostel population, the number of people who had $x$ rays, the number with abnormal $x$ rays (and given an appointment for outpatients), and the number treated are shown in table I. Of a total hostel population of 1250,547 had $x$ rays. Table II shows their age distribution compared with the age distribution of tuberculosis cases from the hostels notified from 1985 to 1987 . Of the 547 
people receiving $x$ ray examinations in this study, two cases of active tuberculosis were found but both were already known to have tuberculosis and were undergoing treatment at the time of the survey. The screening exercise identified five other people with significant diagnoses requiring intervention, which are summarised in table III.

Cost estimates from three different commercial organisations were obtained. The minimum charge for the screening exercise would have been $£ 2200$ at 1987 prices, but covering only clients who were immediately available for $x$ ray on the arrival of the van. Only about two thirds of the clients would have been guaranteed an $x$ ray on this basis.

\section{Discussion}

No new cases of pulmonary tuberculosis were found by the MMR screening procedure among 1250 residents of eight hostels for the single homeless in south east London. Since there is considerable evidence that pulmonary tuberculosis is a major problem among the single homeless men, with prevalence rates for active tuberculosis of around $1 \%, 5-7$ it is important to ask why our screening programme was so unsuccessful in identifying such cases. There are several possible reasons.

First, the incidence of and mortality from tuberculosis have declined considerably over this century, so it may be that in south east London the disease is no longer an important public health problem. However, the evidence is against this. Over the years 1985-1987 there were 475 notifications of tuberculosis from the boroughs
Table I Yield of miniature $\mathrm{x}$ ray screening $(M M R)$ in the hostel population

\begin{tabular}{|c|c|c|}
\hline & $n$ & $o_{o}$ \\
\hline $\begin{array}{l}\text { Resident in/attending the hostels }{ }^{a} \\
\text { Received } x \text { ray }\end{array}$ & $\begin{array}{r}1250 \\
547\end{array}$ & $100 \cdot 0$ \\
\hline $\begin{array}{l}\text { Received } x \text { ray } \\
\text { With an abnormal } x \text { ray (and given an }\end{array}$ & & \\
\hline outpatient appointment) & 48 & $3 \cdot 8$ \\
\hline Arriving for outpatient appointment & 20 & $1 \cdot 6$ \\
\hline Found to have active tuberculosis & 2 & $0 \cdot 2$ \\
\hline $\begin{array}{l}\text { Having any other condition requiring } \\
\text { attention }\end{array}$ & 5 & $0 \cdot 4$ \\
\hline
\end{tabular}

ancluding one day centre

See table III

\begin{tabular}{|c|c|c|c|}
\hline \multirow{3}{*}{$\begin{array}{l}\text { Age } \\
\text { (years) }\end{array}$} & \multicolumn{2}{|c|}{ MMR study responders } & \multirow{2}{*}{$\begin{array}{l}\text { Hostel } \\
\text { dwellers } \\
\text { notified } \\
1985-7\end{array}$} \\
\hline & \multirow{2}{*}{$\begin{array}{l}\text { Residential } \\
\text { hostels } \\
n \quad\left({ }_{0}\right)\end{array}$} & $\begin{array}{l}\text { Day } \\
\text { centre }\end{array}$ & \\
\hline & & $n \quad\left({ }_{0}^{o}\right)$ & $n \quad\left(\begin{array}{c}o \\
0\end{array}\right)$ \\
\hline $16-24$ & $13 \quad(3)$ & (13) & (0) \\
\hline $25-34$ & $37 \quad(7)$ & (26) & (3) \\
\hline $35-44$ & (19) & $10 \quad(26)$ & (14) \\
\hline $45-54$ & (25) & $8(21)$ & (43) \\
\hline $55-64$ & (25) & 5 (13) & (17) \\
\hline $65-74$ & (16) & (0) & (11) \\
\hline & (4) & (3) & (9) \\
\hline Not known & (1) & (0) & $1 \quad(3)$ \\
\hline Total & $508(100)$ & $39(100)$ & $35(100)$ \\
\hline
\end{tabular}

Table II Ages of people attending for miniature $\mathrm{x}$ ray screening ( $M M R$ ) compared with ages of hostel dwellers notified to have tuberculosis, 1985-7

Table III Diagnoses identified and pursued by the screening procedure

\begin{tabular}{ll}
\hline Diagnosis & Management \\
\hline $\begin{array}{l}\text { Tuberculosis (2) } \\
\text { Gastrointestinal bleed (1) }\end{array}$ & $\begin{array}{l}\text { None (both already under treatment) } \\
\text { Severe airflow obstruction and ankylosing } \\
\text { spondylitis (1) }\end{array}$ \\
$\begin{array}{l}\text { Admitted to hospital } \\
\text { Hypeniectasis (1) }\end{array}$ & $\begin{array}{l}\text { Treated in outpatient department } \\
\text { Treated in outpatient department }\end{array}$ \\
Cardiomyopathy (1) & $\begin{array}{l}\text { Referred to general practitioner } \\
\text { Referred to general practitioner }\end{array}$ \\
\hline
\end{tabular}

of Lambeth, Southwark, and Lewisham, a population rate nearly three times greater than that of England and Wales. ${ }^{3}$ Furthermore, over the period 1976-85, the standardised mortality ratios for tuberculosis in each of the three health districts in the area were all well in excess of $250 .^{8}$

Secondly, it is possible there really was a low prevalence of tuberculosis in the study population, ie, in the 1250 hostel residents who were offered chest $x$ rays. Again, this seems unlikely, because during the three years around the time of this study there were 35 notifications of tuberculosis from the eight hostels involved. These represented $7^{\circ}$ of all notifications from the three boroughs for this period (unpublished data from local authority records).

Thirdly and most likely, the explanation may lie in a difference between the whole study population and those who responded, reflecting the method by which residents were recruited or followed up. This is not a simple question of age distribution, as table II shows little difference between responders and hostel dwellers notified with tuberculosis. Nonetheless, the response rates do permit major differences. The response rate to the initial invitation of $44 \%$ is low, although it does not compare badly with other studies of MMR. For example, Patel reported a response rate in Glasgow of $12 \%$, which increased to $47^{\circ}$ 。 using financial inducements, ${ }^{6}$ Capewell achieved response rates in Edinburgh varying between $26^{\circ} \%$ and $64 \% 5$ and Ross only managed to screen $18 \%$ of the residents of common lodging houses in Edinburgh between 1967 and $1971 .{ }^{9}$

The attendance rate for follow up of abnormal $x$ rays was also low, with only $20(42 \%)$ of the 48 of men attending for their outpatient appointment. Similar figures have been reported elsewhere. Trachtman, studying homeless men in New Orleans, found only $14 \%$ attending for appointments following an abnormal $x$ ray. ${ }^{10}$ Whichever the reason for the failure of response to screening, the question of how things could be improved remains.

Within the framework of MMR there is evidence that it is possible to improve results. Patel, ${ }^{6}$ Shanks and Carroll, ${ }^{11}$ and Capewell et al ${ }^{5}$ have all described how, in different cities, they increased both the response rate for screening and the number of cases of tuberculosis diagnosed. They did this by a mixture of financial inducements, regular screening, general encouragement from the hostel staff, ongoing commitment from medical staff, careful record keeping, and enthusiastic follow up of abnormal $x$ rays. That is, they attempted to provide more acceptable and accessible care. However, since we incorporated many of these features into our screening programme, it seems unlikely that there would have been much return for further effort. It is difficult to avoid the conclusion that the sort of service provided in this study is inappropriate for this population.

To compound matters, the mass screening approach organised via hostels is likely to become less relevant and even less cost-effective with increasing dispersal of the homeless population. In 1981, there were 9800 bed spaces available in London in direct access large hostels for single homeless men, but by 1989 this had declined to 
$2500 .^{12}$ At the same time, the size of London's single homeless population is thought to have increased substantially to between 50000 and $70000 . .^{12}$ One of the main criteria for a successful population screening programme is that it should reach its target population, ${ }^{13}$ and to do this it needs to be both accessible and acceptable. In this study, the MMR failed to reach its target population on the grounds of acceptability. In future, it will also increasingly fail on the grounds of accessibility.

In conclusion, we need to develop an alternative approach, which moves away from mass screening altogether. As has been argued, this will probably mean more intensive and continuous primary health care, either organised from district health authorities or from general practice, ${ }^{14}$ although this too needs evaluation. This will not be easy but the need cannot be ignored. This study shows that the alternative, assumed to be effective, was in fact not contributing to the management of an important public health problem.

1 Springett VH. Tuberculosis-epidemiology in England and Wales. $B M \mathcal{F}$ 1972; i: 422-3.
2 Registrar General's Statistical Review of England and Wales. London: HMSO, 1954-1973.

3 DHSS and Welsh Office. Mass Miniature Radiography Service HM (69) 97, 1969, London, Cardiff

4 DHSS. Chest disease and tuberculosis in homeless and rootless persons. Letter to AMOs and RMOs. July 1977

5 Capewell S, France AJ, Anderson M, Leitch G. Th diagnosis and management of tuberculosis in common hote dwellers. Tubercle 1986; 67: 125-31.

6 Patel KR. Pulmonary tuberculosis in residents of lodging houses and common hotels in Glasgow: 5 year prospective study. Br $\mathcal{F}$ Dis Chest 1985; 79: 60-6.

7 Ramsden SS, Baur S, El Kabir DJ. Tuberculosis among the central London single homeless. a four-year prospective study. F $R$ Coll Physicians Lond 1988; 22: 16-17.

8 Charlton J, Holland WW, Lakhani A, Paul EA Variation in avoidable mortality and variations in health care. Lancet 1987; i: 858 .

9 Ross JD, Reid DG, Jamieson A. Pulmonary tuberculosis in the common hostel populations. Update 1977; 7: 167-74.

0 Trachtman L, Greenberg HB. Surveying 2000 vagrants for tuberculosis (letter). $\mathcal{F} A M A$ 1978; 240: 739

11 Shanks NJ, Carroll KB. Improving the identification rate of pulmonary tuberculosis amongst inmates of common lodging houses. I Epidemiol Community Health 1982; 36: $130-2$.

12 Eardley T. Move on housing. The permanent housing needs of residents of hostels and special needs housing projects in London. Single Homeless in London Working Party (SHIL); London, 1989.

13 Cochrane A, Holland WW. Validation of screening procedures. Br Med Bull 1971; 27: 3-8.

14 Brocedures. Br people people in London: a strategic approach. Report of the homelessness in London (SHIL); London, 1987. 